E3S Web of Conferences 2, 02001 (2014)

DOI: $10.1051 / \mathrm{e} 3$ sconf/ 20140202001

C) Owned by the authors, published by EDP Sciences, 2014

\title{
World Mineral resources and the Limits to Economic Growth
}

\author{
Ugo Bardi \\ Dipartimento di Scienze della Terra - Università di Firenze \\ c/o Polo Scientifico di Sesto Fiorentino, via della Lastruccia 3 \\ 50019 Sesto Fiorentino, Firenze, Italy
}

\begin{abstract}
This presentation describes how the present economic situation can be described in terms of the system dynamics models developed in the series of studies that were titled "The Limits to Growth". The result of this examination is that mineral depletion may be a major factor in causing the slowdown in economic growth in several countries. The effect is not the result of "running out" of any resource, but of the gradual increase in extraction costs which is forcing the economy to dedicate larger and larger resources to the production of mineral commodities.
\end{abstract}

\section{Introduction}

This text is dedicated to a discussion of the relevance of mineral resources to the economy. It is the result of a research program sponsored by the Club of Rome which has been published under the title of "the Plundered Planet." [1] The basic point of the study is related to how depletion is affecting the mineral industry. On this point, several elements can be taken as a measure of these effects ; namely 1) the remaning mineral resources, 2) the production trends 3 ) the prices of mineral commodities and 4) non linear models based on system dynamics.

The conclusion of this assessment is that there exist important constraints to economic growth correlated to the increasing scarcity of mineral resources. Climate change is also starting to appear as an important limiting factor in reducing the ability of the economy to build up capital resources.

\section{Discussion}

\subsection{The reserves/production approach}

The geology based evaluation of the available mineral resources is often the most common way of discussing depletion. In this approach, the results are often optimistic, especially if the evaluation is coupled with the estimation of the "reserves to production" ratio $(\mathrm{R} / \mathrm{P})$. This ratio is obtained by dividing the amount of reserves - estimated from geological parameters - to the current production rate. It produces estimates that are normally described as " number of production years remaining.» As this number turns out to be at least in the region of decades for most mineral resources being produced today, the normal conclusion is that depletion is not a problem for the foreseeable future (see e.g. [2], [3]). 
The $\mathrm{R} / \mathrm{P}$ approach is very common within the mineral industry, but the associated problems are multiple. First, the estimation of reserves is based mainly on geological data. But a "Reserve » is not a geological concept; it is an economic one. Reserves, by definition, are those mineral deposits that can be extracted at a profit. So, the only way to determine if a certain deposit is a reserve is to verify that it is actually extracted. But that's hardly a way to forecast the future. Secondly, the use of the current production data as if it were constant is arbitrary, to say the least. In history, it has never occurred that a mineral commodity has been produced at a costant rate for an extended period of time. So, the $\mathrm{R} / \mathrm{P}$ ratio can, at best, provide a comparison of the relative abundance of different resources, but gives no useful information about the effects of depletion on production.

\subsection{Production trends}

The evaluation based on production trends is usually qualitative. Noting that a certain commodity has been produced at increasing rates during the past can be taken as an indication that the trend will continue. That may well be justified in some cases, but predicting the future by extrapolating of past trends is, as well known, risky (that's the well known case of "the man who jumps off the Empire State Building and says how great things are going so far as he passes the 10th floor", as Paul Ehlrich is quoted to have [4]). Nevertheless, even a qualitative examination of the production trends can usually provide useful data on the status of a certain mineral commodity. For instance, at present, some commodities show worldwide near-exponential growing trends; for instance cement is possibly the fastest growing mineral commodity currently produced [5]. That is compatible with the fact that cement mineral resources are abundant and are likely to remain so as long as the world's economy maintains a strong demand for cement.

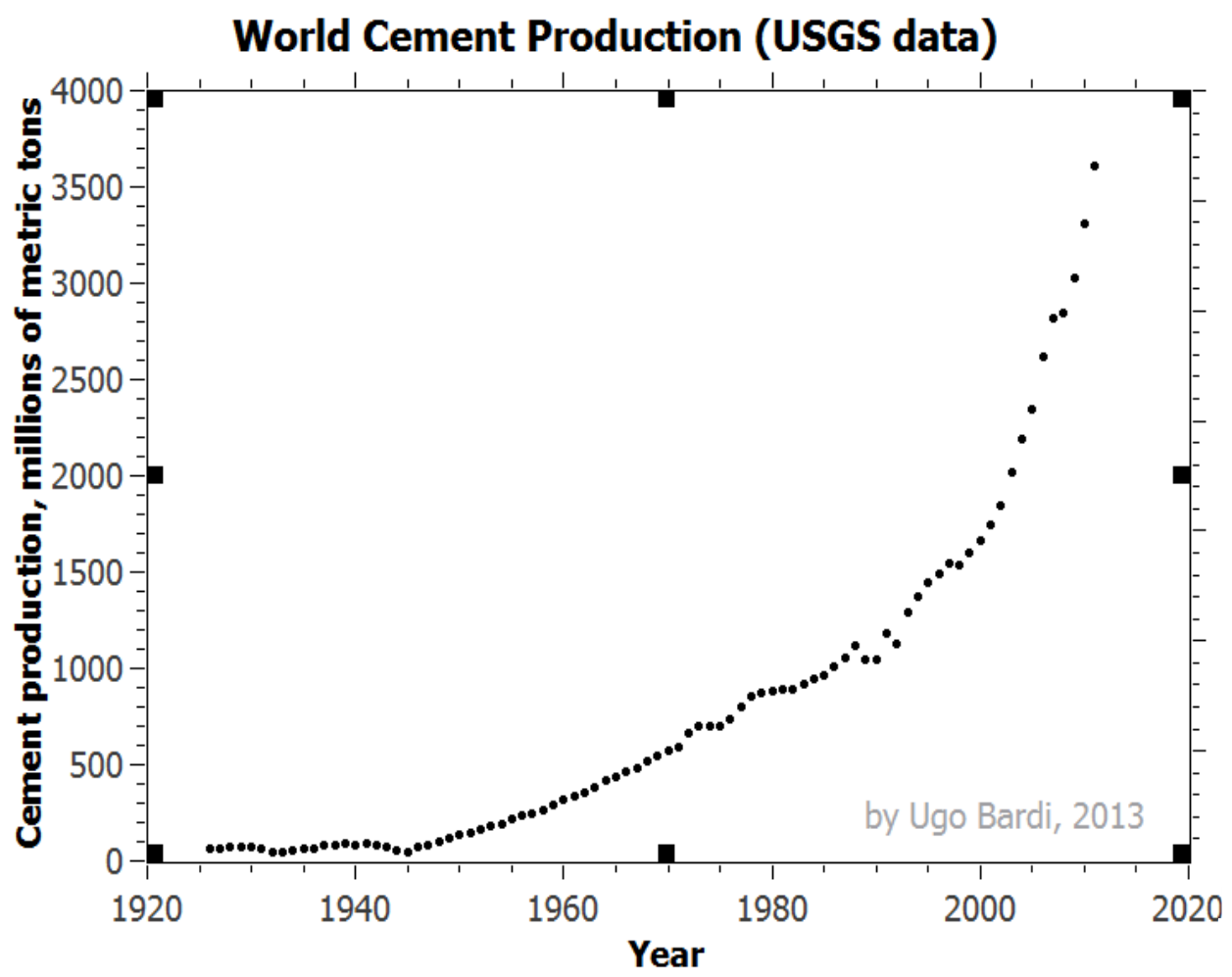

Figure 1. World cement production. Data from the United States Geological Service (USGS) [5] 
Other commodities clearly show different trends. For instance, here is a plot of the world's production of copper from mines. The fact that production is tapering down indicates increasing costs and difficulties in the exploitation of the resource.

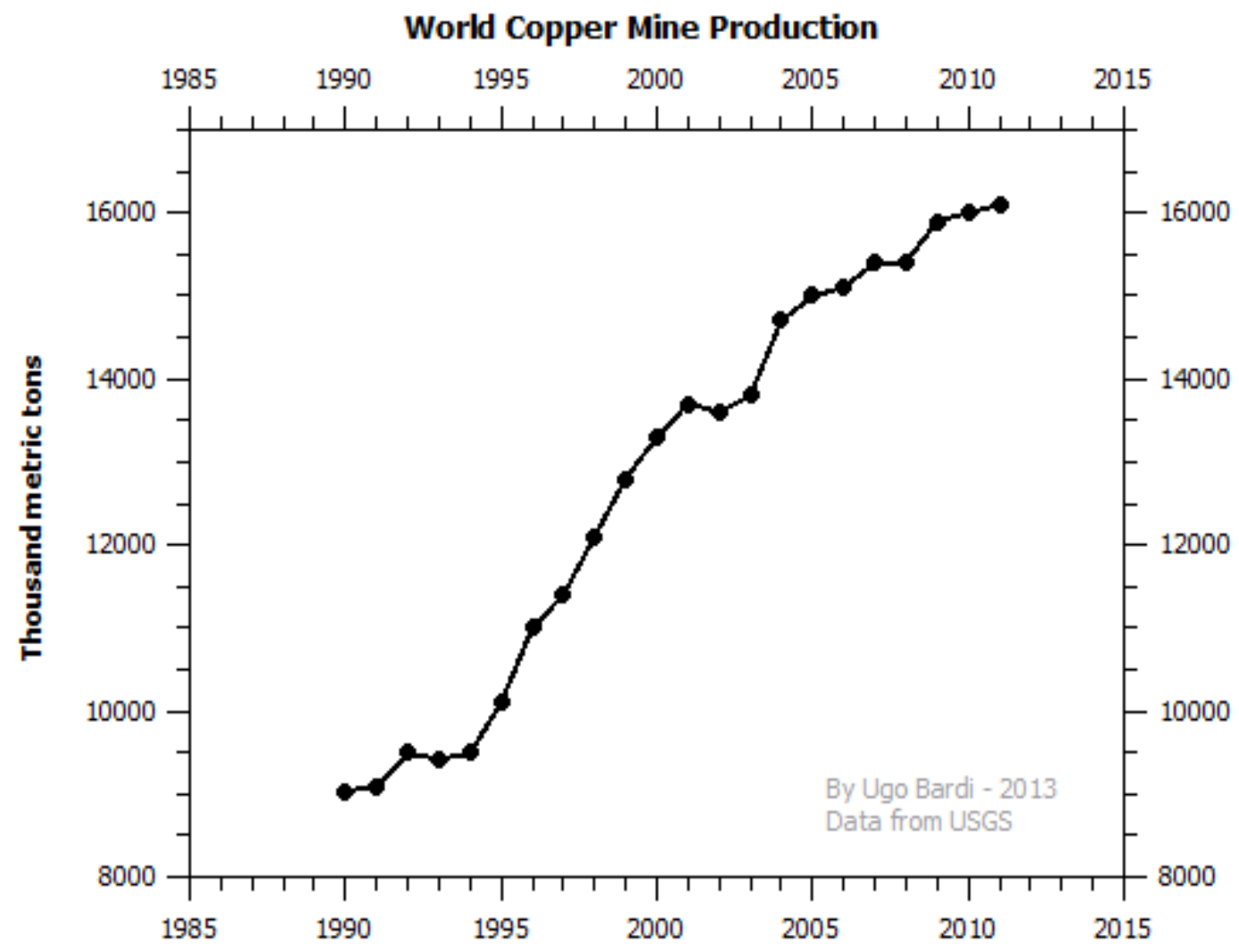

Figure 2. Copper world production - data from USGS [6]

\subsection{Prices}

Prices have long been considered a good indicator of the scarcity of a mineral resource, from the time when the well-known "Hotelling » model was proposed in the 1930s [7]. On the basis of some drastic simplifications, Hotelling had proposed that the prices of an exhaustible resource should rise as extraction progresses. This is intuitively sensible, although it should be understood to be valid only within the rather narrow limits of the model's assumptions. Of these, probably the most unrealistic ones are that the price of extraction does not vary as the resource is exploited and that the firm that carries out extraction is a "perfect monopolist» whose managers try to optimize economic returns in the long term. In practice, it is clear that the real world is different and that price trends can be affected by a host of other factors, such as scale factors and technological improvements. Given this point, it is clearly unjustified to assume that a declining trend in prices indicates that a resource has been exploited only as a minimal fraction of the available resources [8] or even that it is infinite or destined to last « billions of years » [2]. 
However, there exists a basic logic in the fact that prices are an indication of scarcity in a market economy and that can be used - with some caution - to estimate the availability of a world resource and whether depletion problems are playing a role. Taking again copper as an example, we can plot the price trends as follows :

\section{Copper Prices}

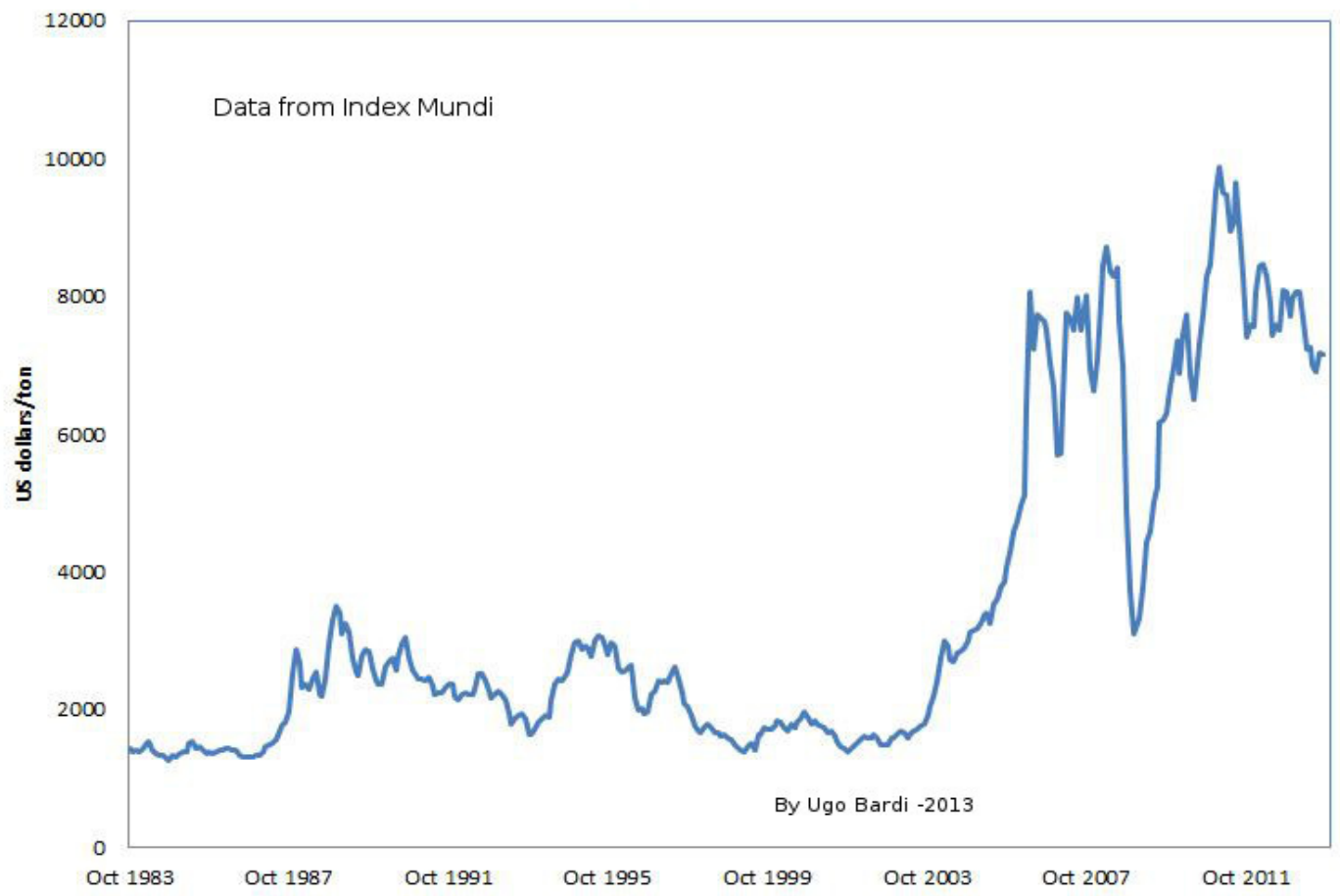

Figure 3. Copper price during the past 30 years (not corrected for inflation). Data from « Index Mundi »[9]

The rise in copper prices is not isolated, many metals and relatively rare commodities have shown such an increase (see, e.g. [10]). This increase may not be directly related to the actual depletion of the commodity, but to the increase in energy prices shown by all the fossil fuel commodities. For instance, here are the trends for oil prices.

The rise of oil prices has often been attributed to speculation in the past, but the robust trend that started in the early 2000 s must be clearly attributed to some structural causes. Indeed, it is very well known that depletion is an increasing difficult problem for the oil industry and the recent emphasis on the "New Oil" resources and the related technological progress is evidence that the problem is there. That doesn't mean that oil prices are destined to grow forever, but they will remain high as long as demand remains strong because the cost of extraction is high enough to make these prices necessary if production must remain at the present levels.[12]. 


\section{Brent Oil Prices}

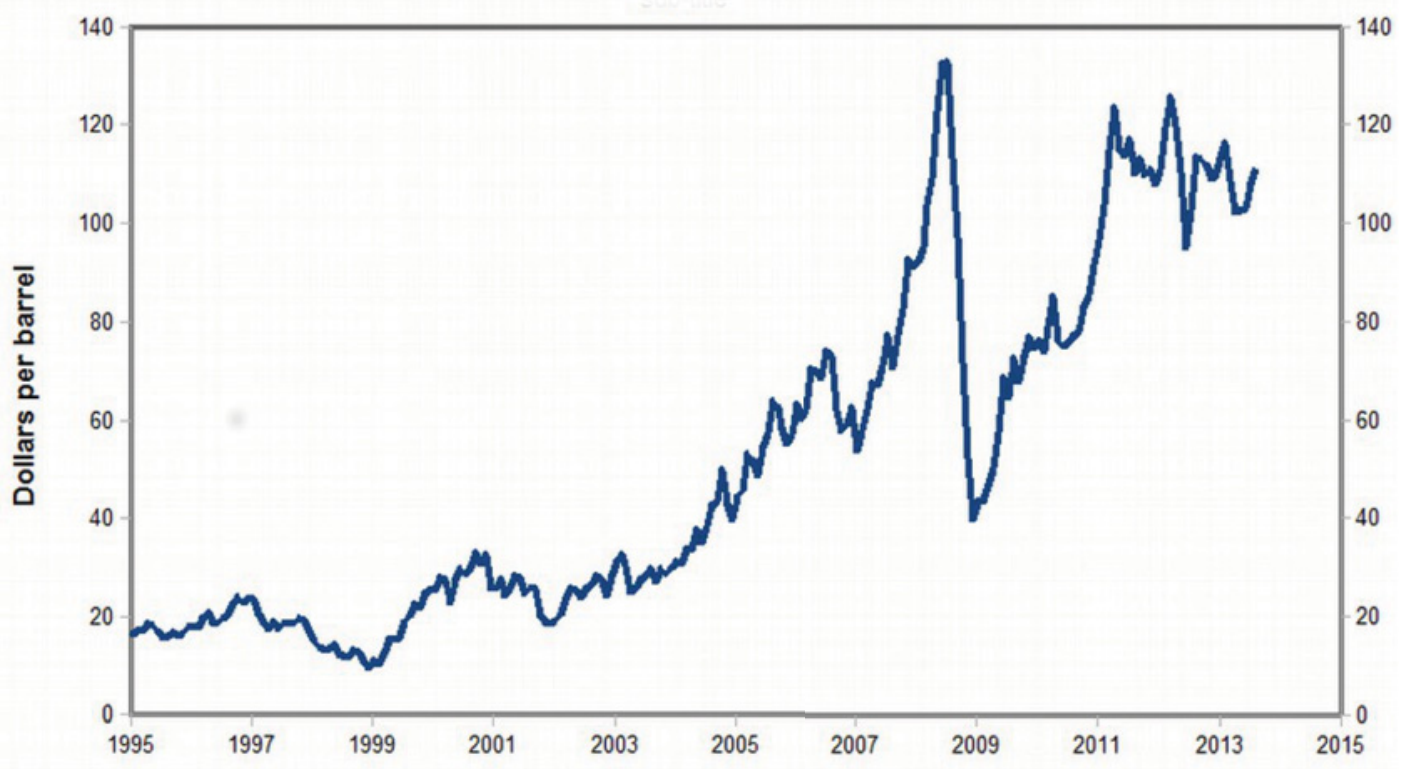

Figure 4. Brent oil prices, data from the Energy Information Agency [11]

\subsection{Non-linear models}

This approach is based on all those models which attempt to understand the behavior of the productive system in terms of the non-linear interaction of the costs related to the scarcity of the resource and of the economic system. In a way, the Hotelling model [7] is part of this family, but it is truly too simplified to be considered as useful for any kind of understanding the effect of depletion [13], [14]. Also the original Hubbert model [15] can be considered as part of this category, at least in the sense that the production curve it generates is strongly non linear (it is "bell shaped"). However, the Hubbert model is a purely empirical model that only recently has been demonstrated to be equivalent to more complex dynamical models [16]. So, I will consider here only the family of models that go under the name of "system dynamics" models. For the purpose of the present paper, I will consider only the origin of all these models, the "World3" one which was the basis of the study published for the first time in 1972 with the title "The Limits to Growth" [17] and was later updated, the most recent times in 2004 [18].

The Limits to Growth model [19] was thought from the beginning as coupling a certain number of aggregated factors that included the world's industrial economy, the agricultural system, the mineral production system, population and pollution. It was a complex study based on the best available data at the time and that used the most sophisticated computers available to study how the interaction of various factors would affect parameters such as industrial production, agricultural production, population and the like. Here are the results for the "base case" scenario as found in 2004 [18]. 


\section{State of the World}

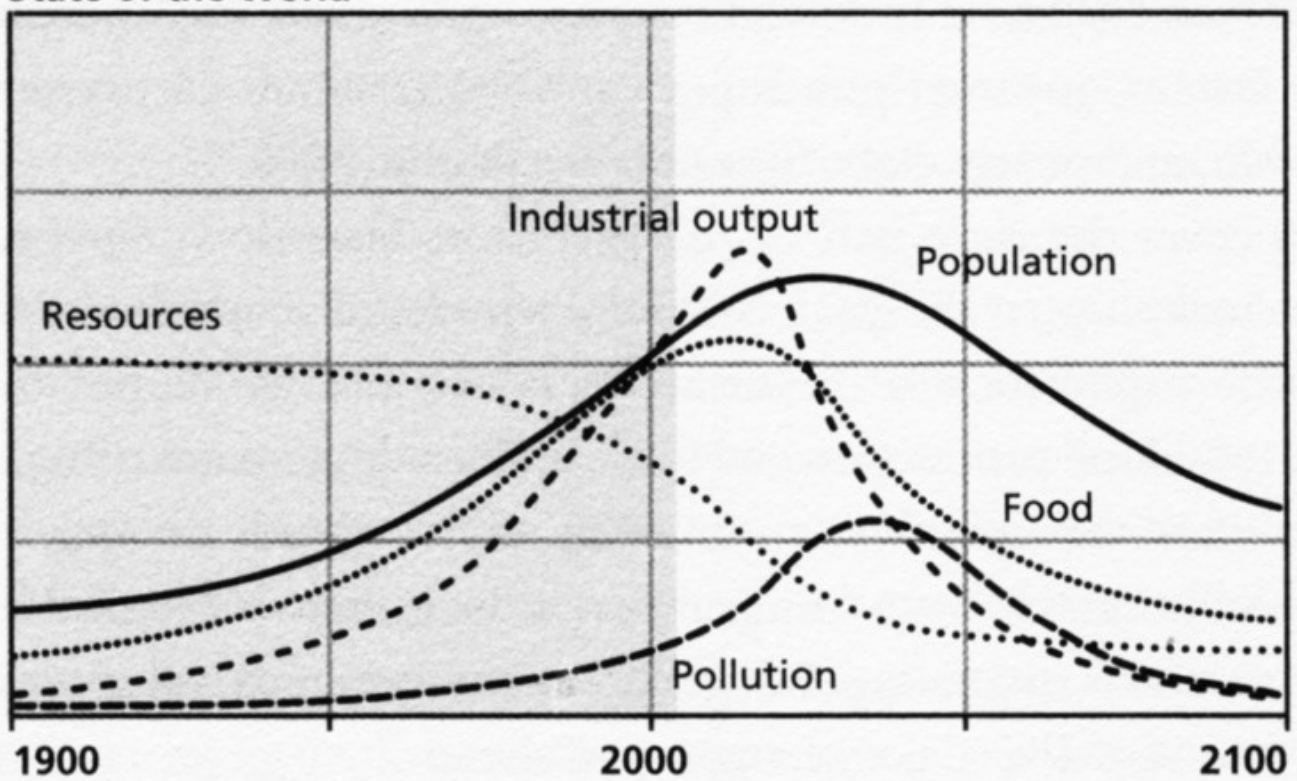

Figure 5. The "base case" scenario from the 2004 edition of "The Limits to Growth", showing the evolution of the main parameters of the world system (Image courtesy of Dennis Meadows). These results are very general and robust independently of the kind of initial assumptions; within the idea that economic operators would normally make their choices in order to optimize their monetary gains.

In a "dynamic" model, such as World3, all the elements of the economic system interact with each other; either reinforcing each other (positive feedback) or weakening each other (negative feedback). The physical reasons that generate the bell shaped curve are related to the fact that the economy is a thermodynamic engine. Fossil fuels are mined in order to obtain energy, but to do so, expending energy is necessary. This tradeoff can be expressed in terms of « Energy Return for Energy Invested » (EROI or EROEI) [20]. The higher this ratio, the higher the amount of energy that the resource can provide. That holds for all energy producing minerals, oil, gas and the like, and you wouldn't be surprised to learn that this ratio tends to go down as you keep exploiting your resource. The problem of diminishing yields exists also for minerals that are not extracted in order to produce energy. You still have to spend energy in order to extract all minerals and, as depletion sets in, you have to use more and more energy. That makes the resource more expensive. And there is no doubt that this process is ongoing. You need huge amounts of energy to mine the amount of mineral commodities that the industrial society needs.

To understand how the economy reacts to these physical constraints, it is important to consider the role of the "capital" parameter. The behavior of the capital stock directly affects industrial production and other parameters which are counted as part of economic indicators such as the gross domestic product (GDP). In the model, "capital" is created by investments generated by industrial activity. Capital is assumed to decay at a rate proportional to the amount of existing capital. This is called obsolescence or, sometimes, depreciation. To keep capital growing, or at least not disappearing, investments need to be larger than, or as large as, depreciation. Since investments depend on the availability of natural resources, the buildup (or the dissipation) of the capital stock depend on the progressive depletion of these resources. In the original LTG model of 1972, there were three kinds of capital stocks considered: industrial capital (factories, machines, etc.), service capital (schools, bridges, hospitals, etc.) and agricultural capital (farms, land, machinery, etc.). In the latest version 
(2004), industrial capital and mining capital are considered separately and the "capital" parameter (in its various forms) affects the parameters which determine the GDP.

Here is a description of how capital interacts with the other elements of the world model written in 1972 by the authors of the LTG report [21]:

The industrial capital stock grows to a level that requires an enormous input of resources. In the very process of that growth it depletes a large fraction of the resource reserves available. As resource prices rise and mines are depleted, more and more capital must be used for obtaining resources, leaving less to be invested for future growth. Finally investment cannot keep up with depreciation, and the industrial base collapses, taking with it the service and agricultural systems, which have become dependent on industrial inputs.

At this point, it is possible to understand the reasons of the "bell shaped" curve. Depletion is not an "all or nothing" phenomenon. It is a gradual evolution in which mining becomes more and more expensive; that means both in terms of energy needed and in terms of money. As your profit gradually wane, the industry is left with less and less resources to invest in further mining. So, growth slows down, it arrives to a peak and then declines.

Of course, there are many more factors influencing the curve, prices, political interventions, technology, etcetera. But the core of the model, the decline of net energy, remains a powerful factor in shaping the production curves, which, in turn, affect the economy and generate a global decline.

A last point, but by far not the least important. In the model, the decline of the industrial society is the result not of just depletion but of pollution as well. With the first study of 1972, the authors couldn't exactly pinpoint what was the main factor that generated this problem, but now we know that it is the emission of greenhouse gases, mainly $\mathrm{CO} 2$. But with time, climate change is being recognize more and more as important factor affecting the economy. Climate change and resource depletion are not two separate problems. They are two sides of the same problem.

\section{Conclusion}

There are many models and many way to understand the hugely complex thing which is the world's industrial and agricultural system in its interaction with the availability of mineral commodities. Something that can be said for sure, however, is that mineral resources, in the highly concentrate form that go under the name of "ores", are a limited resource and therefore it will not be possible to extract and produce them forever. That doesn't mean we will "run out" of anything but, more simply, that at some point in the future, extracting those minerals that are today at the basis of our industry will become too expensive for the system to afford (assuming that climate change will not force the industry to stop extracting fossil resources even before, because of the disastrous effects of climate change). This concept had been already expressed in $19^{\text {th }}$ century by William Stanley Jevons [22].

Therefore, the future industrial system, if there will be one, will have to be based on resources that are completely different than the present ones and on sources of energy which will have to be renewable and non polluting. Possible strategies based on renewable technology (e.g. solar and wind) and on the use of elements which are abundant in the Earth's crust (e.g. aluminum, titanium and silicon) are discussed in [1] and [23]. In general, we cannot predict the future, but we are all going there and we can as well try to understand it before we arrive to our destination. 


\section{References}

1. U. Bardi, Der geplünderte Planet, Neuausg. Oekom, 2013.

2. J. Simon, The Ultimate Resource. Princeton University Press, 1981.

3. P. R. Odell, "Reports of the oil industry's imminent death are greatly exaggerated," The Guardian, Feb-2008.

4. J. Simon, "The ultimate Resource 2. Princeton University Press," Princeton, New Jersey, 1996.

5. J. J. Barry, R. Matos, Grecia, and D. " Menzie, "U.S. Mineral Dependence-Statistical Compilation of U.S. and World Mineral Production, Consumption, and Trade, 1990-2010," 2013.

6. D. Kramer, "U.S. Geological Survey, Mineral Commodity Summaries, January 201,” 2013.

7. H. Hotelling, "The Economics of Eshaustible Resources," J. Polit. Econ., vol. 39, no. 2, pp. $137-175,1931$.

8. H. S. Houthakker, “Are minerals exhaustible?," Q. Rev. Econ. Financ., vol. 42, no. 2, pp. 417-421, 2002.

9. "Index Mundi: commodity prices." [Online]. Available: http://www.indexmundi.com/commodities/. [Accessed: 05-Nov-2013].

10. C. Bertram, A. Krätschell, K. O’Brien, W. Brückmann, A. Proelss, and K. Rehdanz, "Metalliferous sediments in the Atlantis II Deep-Assessing the geological and economic resource potential and legal constraints," Resour. Policy, vol. 36, no. 4, pp. 315-329, Dec. 2011.

11. "Spot Prices: Energy Information Agency (EIA)." [Online]. Available: http://www.eia.gov/dnav/pet/pet_pri_spt_s1_d.htm. [Accessed: 02-Nov-2013].

12. J. Hamilton, "Understanding crude oil prices," 2008.

13. R. Hart and D. Spiro, "The elephant in Hotelling's room," Energy Policy, vol. 39, no. 12, pp. 7834-7838, Dec. 2011.

14. D. B. Reynolds and J. Baek, "Much ado about Hotelling: Beware the ides of Hubbert," Energy Econ., vol. 34, no. 1, pp. 162-170, 2012.

15. M. K. Hubbert, "Nuclear Energy and the Fossil Fuels," in Spring Meeting ofthe Southern District Division of Production American Petroleum Institute, 1956.

16. U. Bardi and A. Lavacchi, “A Simple Interpretation of Hubbert's Model of Resource Exploitation," Energies, vol. 2, no. 3, pp. 646-661, Aug. 2009.

17. D. H. Meadows, D. L. Meadows, J. Randers, and W. Bherens III, The Limits to Growth. New York: Universe Books, 1972.

18. D. H. Meadows, J. Randers, and D. L. Meadows, Limits to Growth: the 30 year update. White River Junction: Chelsea Green, 2004.

19. A. Meadows, Dennis, William, W., Behren III, Donella Meadows, Roger F., Naill, Jorgen Randers and Z. Erich K.O., Dynamics of Growth in a Finite World. Cambridge: Wright Allen Press, 1974.

20. D. Murphy and C. Hall, "Energy return on investment, peak oil, and the end of economic growth," Ann. New York Acad. ..., 2011.

21. D. L. Meadows, "The Limits to Growth." [Online]. Available: cms.unige.ch/isdd/IMG/rtf/limits-2.rtf.' [Accessed: 14-Nov-2013].

22. W. S. Jevons, The Coal Question, 2nd revised edition. Macmillan and Co, 1866, p. 25.

23. U. Bardi, "Energy and Mining," Front. Energy Syst. Policy, vol. In Press, 2013. 